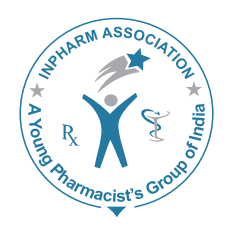

\title{
JYP
}

\section{Formulation and Optimization of Mucoadhesive Nanodrug Delivery System of Acyclovir}

\author{
Bhosale UV, Kusum Devi V, Jain N \\ Department of Pharmaceutics, Al-Ameen College of Pharmacy, Bangalore - 560 027, India \\ Address for correspondence: Mr. Uday Bhosale; E-mail: udaybhosale25@gmail.com
}

\begin{abstract}
Acyclovir is an antiviral drug used for the treatment of herpes simplex virus infections, with an oral bioavailability of only 10-20\% [limiting absorption in gastrointestinal tract to duodenum and jejunum] and half-life of about $3 \mathrm{~h}$, and is soluble only at acidic $\mathrm{pH}$ (pKa 2.27). Mucoadhesive polymeric nanodrug delivery systems of acyclovir have been designed and optimized using $2^{3}$ full factorial design. Poly (lactic-co-glycolic acid) (PLGA) (50:50) was used as the polymer along with polycarbophil (Noveon AA-1) as the mucoadhesive polymer and pluronic F68 as the stabilizer. From the preliminary trials, the constraints for independent variables $X_{1}$ (amount of PLGA), $X_{2}$ (amount of pluronic F68) and $X_{3}$ (amount of polycarbophil) have been fixed. The dependent variables that were selected for study were particle size $\left(\mathrm{Y}_{1}\right)$, \% drug entrapment $\left(\mathrm{Y}_{2}\right)$ and \% drug release in $12 \mathrm{~h}\left(\mathrm{Y}_{3}\right)$. The derived polynomial equations were verified by check point formulation. The application of factorial design gave a statistically systematic approach for the formulation and optimization of nanoparticles with the desired particle size, $\%$ drug release and high entrapment efficiency. Drug: Polymer ratio and concentration of stabilizer were found to influence the particle size and entrapment efficiency of acyclovir-loaded PLGA nanoparticles. The release was found to follow Fickian as well as non-Fickian diffusion mechanism with zero-order drug release for all batches. In vitro intestinal mucoadhesion of nanoparticles increased with increasing concentration of polycarbophil. These preliminary results indicate that acyclovir-loaded mucoadhesive PLGA nanoparticles could be effective in sustaining drug release for a prolonged period.
\end{abstract}

Key words: $2^{3}$ factorial design, acyclovir, mucoadhesive, nanoparticles, poly (lactic-co-glycolic acid)

\section{INTRODUCTION}

Herpes simplex virus (HSV) is a member of the family of herpes viridae, a DNA virus. There are two types of HSV, viz., HSV type 1 and type 2 . HSV type 1 is the herpes virus

\begin{tabular}{|l|l|}
\hline \multicolumn{2}{|c|}{ Access this article online } \\
\hline Quick Response Code: & \multirow{2}{*}{ Website: } \\
\hline & www.jyoungpharm.in \\
& \\
\hline
\end{tabular}

that is usually responsible for cold sores of the mouth, the so-called fever blisters. HSV type 2 is the one that most commonly causes genital herpes. ${ }^{[1]}$ The infection causes painful sores on the genitals in both men and women. In addition, herpes sores provide a way for HIV to get past the body's immune defenses and make it easier to get HIV infection. A recent study found that people with HSV had three times the risk of becoming infected with HIV as compared to people without HSV. ${ }^{[2]}$ Currently, the treatments available for herpes simplex are conventional tablets and topical gel for application on outbreaks. The drugs that are commonly used for herpes simplex are acyclovir, valaclovir and famciclovir. 
Acyclovir, the first agent to be licensed for the treatment of HSV infections, is the most widely used drug for infections such as cutaneous herpes, genital herpes, chicken pox, and varicella zoster. Acyclovir is currently marketed as capsules (200 mg), tablets (200 mg, $400 \mathrm{mg}$ and $800 \mathrm{mg}$ ) and topical ointment. ${ }^{[1]}$ Oral acyclovir is mostly used as $200 \mathrm{mg}$ tablets, five times a day. In addition, long-term administration of acyclovir ( 6 months or longer) is required in immunocompromised patients with relapsing herpes simplex infection. ${ }^{[2]}$ The presently available conventional therapy is associated with a number of drawbacks such as highly variable absorption and low bioavailability (10-20\%) after oral administration. ${ }^{[3]}$ Furthermore, with increase in dose, there is decrease in bioavailability. Moreover, because the mean plasma half-life of the drug is $2.5 \mathrm{~h}$, five times a day administration is required. In order to make oral therapy of acyclovir more patient compliant, there is a need of using different approaches like matrix tablets, nanoparticles ${ }^{[4]}$ and polymeric films. ${ }^{[5]}$

The main problem with the therapeutic effectiveness of acyclovir is its absorption which is highly variable and dose dependent, thus reducing the bioavailability to $10-20 \%{ }^{\left[{ }^{[6]}\right.}$ Acyclovir is soluble in acidic $\mathrm{pH}$ and is predominantly absorbed from upper gastrointestinal tract (GIT) ${ }^{[7]}$ There are indications of its active absorption from the duodenum and jejunum regions of GIT. ${ }^{[8]}$

The inherent shortcomings of conventional drug delivery and the potential of nanoparticles as drug delivery systems have offered tremendous scope for researchers in this field and there is a fast movement from concept to reality. Nanoparticles may be used for oral administration of gut-labile drugs or those with low aqueous solubility. ${ }^{[9]}$ These colloidal carriers have the ability to cross the mucosal barrier as such. In addition, they have the potential for enhancing drug bioavailability via particle uptake mechanisms. It was therefore decided to prepare nanoparticles of acyclovir so as to optimize its delivery and overcome its inherent drawbacks.

The concept of mucosal adhesives or mucoadhesives was introduced into the controlled drug delivery arena in the early 1980s. ${ }^{[10]}$ Mucoadhesives are synthetic or natural polymers which interact with the mucus layer covering the mucosal epithelial surface and mucin molecules constituting a major part of the mucus. They localize the formulation at a particular region of the body, thereby improving bioavailability of the drugs with low bioavailability. The increased contact time and localization of the drug due to applying nanoparticles of acyclovir which are made mucoadhesive thus enhances its delivery. Possible added advantage of this approach would be increase in bioavailability as well as reduction in frequency of administration.

For the present investigation, mucoadhesive polymeric nanodrug delivery systems of acyclovir have been designed and optimized using $2^{3}$ full factorial design. Poly (lactic-co-glycolic acid) (PLGA) (50:50) was used as the polymer along with polycarbophil (Noveon AA-1) used as the mucoadhesive polymer and pluronic F68 was used as the stabilizer.

\section{MATERIALS AND METHODS}

Acyclovir was a gift sample from Ajanta Pharmaceutical Limited (Mumbai India); poly (D, L lactide-co-glycolide) (PLGA 50:50 and PLGA 85:15) were obtained as gift samples from Indena Ltd. (Rome, Italy); pluronic F68 and polycarbophil (Noveon AA-1) were procured from Strides Arcolab, (Bangalore, India) as a gift; acetone and cellophane membrane were purchased from S. D. Fine Chem. Ltd. (Mumbai, India). All other reagents and chemicals used in this study were of analytical grade.

\section{Methods}

\section{Mucoadhesive PLGA nanoparticles}

Mucoadhesive PLGA nanoparticles were prepared by the solvent deposition method. Acyclovir was dissolved at $35-40^{\circ} \mathrm{C}$ in neutral water containing a hydrophilic surfactant at various concentrations. A mucoadhesive polymer, polycarbophil, was dispersed in this aqueous phase. Organic phase was prepared by solubilizing PLGA in acetone at various concentrations. The organic phase was poured into the aqueous solution drop wise, under stirring (RPM 5000) for $2 \mathrm{~h}$, thus forming a milky colloidal suspension. The organic solvent was then evaporated by using a Rota evaporator. The resultant dispersion was dried using a freeze drying method. ${ }^{[11,12]}$

\section{Experimental design}

The formulations were fabricated according to a $2^{3}$ full factorial design, allowing the simultaneous evaluation of three formulation variables and their interaction. The experimental designs with corresponding formulations are outlined in Table 1 . The dependent variables that were selected for study were: Particle size $\left(\mathrm{Y}_{1}\right), \%$ drug entrapment $\left(\mathrm{Y}_{2}\right)$ and $\%$ drug release in $12 \mathrm{~h}\left(\mathrm{Y}_{3}\right)$.

\section{In vitro characterization of PLGA nanoparticles}


Table 1: Experimental design and parameters for $2^{3}$ full factorial design batches

\begin{tabular}{lccccccc}
\hline $\begin{array}{l}\text { Batch } \\
\text { code }\end{array}$ & \multicolumn{2}{c}{$\begin{array}{c}\text { Variable level in } \\
\text { coded form }\end{array}$} & $\begin{array}{c}\text { Particle } \\
\text { size }\end{array}$ & $\begin{array}{c}\text { \% Drug } \\
\text { entrapment }\end{array}$ & $\begin{array}{c}\text { \% Drug } \\
\text { release } \\
\text { in 12 h }\end{array}$ & $\begin{array}{c}\text { Average \% } \\
\text { intestinal } \\
\text { retention }\end{array}$ \\
\hline & $\mathbf{X}_{3}^{\S}$ & $\mathbf{X}_{1}{ }^{*}$ & $\mathbf{X}_{2}^{\#}$ & $(\mathbf{n m})$ & & 54.04 & 49.3 \\
MF1 & +1 & +1 & +1 & 1580 & 93.7 & 52.1 \\
MF2 & -1 & $+1-1$ & +1 & 1210 & 89.9 & 59.52 & 62.7 \\
MF3 & +1 & -1 & +1 & 1630 & 94.1 & 53.32 & 45.7 \\
MF4 & -1 & +1 & +1 & 1420 & 88.12 & 57.35 & 55.6 \\
MF5 & +1 & +1 & -1 & 870 & 84.12 & 65.33 & 56.2 \\
MF6 & -1 & -1 & -1 & 740 & 80.16 & 71.14 & 67.3 \\
MF7 & +1 & -1 & -1 & 914 & 86.26 & 63.72 & 52.5 \\
MF8 & -1 & -0.5 & -1 & 810 & 80.09 & 67.02 & 59.7 \\
C & -0.5 & & -0.5 & 1107 & 80.59 & 64.43 & - \\
\hline
\end{tabular}

*For PLGA (50:50) $\left(\mathrm{X}_{1}\right)$ transformed levels in polymer weight are: $-1=175 \mathrm{mg}$; $+1=250 \mathrm{mg} ;-0.5=193.75 \mathrm{mg}$. "For surfactant (pluronic F68) $\left(\mathrm{X}_{2}\right)$ transformed levels in $\%$ are: $-1=0.20 \% ;+1=0.30 \% ;-0.5=22.5 \%$. ${ }^{8}$ For mucoadhesive polymer (polycarbophil) $\left(\mathrm{X}_{3}\right)$ transformed levels in $\%$ are: $-1=0.10 \% ;+1=0.15 \%$; $-0.5=11.25 \%$

\section{Determination of particle size}

The particle size and size distribution of the acyclovir-loaded mucoahesive PLGA (50:50) nanoparticles were characterized by laser light scattering using Particle size Analyzer (Malvern Mastersizer Hydro-2000 SM, UK). The obscuration level was set between 7 and $11 \%$, and distilled water was used as the medium.

\section{Determination of encapsulation efficiency}

The free drug was estimated by taking said quantity of formulation in a dialysis bag (cellophane membrane, molecular weight cutoff 10,000-12,000 Da; Hi-Media, Mumbai, India) which was tied and placed into $100 \mathrm{ml}$ water $(\mathrm{pH}=7)$ maintained at $37 \pm 5^{\circ} \mathrm{C}$ on magnetic stirrer. At predetermined time intervals, $5 \mathrm{ml}$ of the sample was withdrawn by means of a syringe. The volume withdrawn at each interval was replaced with the same quantity of fresh water $(\mathrm{pH}=7)$ maintained at $37 \pm 5^{\circ} \mathrm{C}$. The samples were analyzed for free drug by measuring the absorbance at $252 \mathrm{~nm}$ using UV/Vis spectrophotometer (ShimadzuUV-1700) after suitable dilution. The above-described process of withdrawing sample and analysis was continued till a constant absorbance was obtained. ${ }^{[13]}$

Encapsulated drug was estimated by taking residue formulation remaining behind in the dialysis membrane after the estimation of free drug content, as described above. Formulation in dialysis bag was added to acetone $(10 \mathrm{ml})$ to dissolve PLGA and filtered. The residue remaining on filter paper was dissolved in $100 \mathrm{ml}$ of water $(\mathrm{pH}=7)$ maintained at $37 \pm 5^{\circ} \mathrm{C}$, and after removing the supernatant, the sample was analyzed for drug content by measuring the absorbance at $252 \mathrm{~nm}$ using UV/Vis spectrophotometer (Shimadzu UV-1700) after suitable dilution. The percentage of drug entrapped and the percentage of free drug were calculated using the following equations: ${ }^{[14]}$

$$
\begin{gathered}
\begin{array}{c}
\text { Amount of free drug present in } \\
100 \mathrm{mg} \text { of formulation }
\end{array} \\
\begin{array}{c}
\text { Total amount of drug present } \\
\text { in } 100 \mathrm{mg} \text { of formulation }
\end{array} \\
\text { Amount of encapsulated } \\
\text { drug present in } 100 \mathrm{mg}
\end{gathered}
$$

Statistical analysis

The results from factorial design were evaluated using Sigma plot software (Systat Software Inc., Version 3.0, Richmond, CA software). Step-wise backward linear regression analysis was used to develop polynomial equations for dependent variables ${ }^{[15,16]}$ such as particle size $\left(Y_{1}\right) \%$ drug entrapment $\left(\mathrm{Y}_{2}\right)$ and $\%$ drug release in $12 \mathrm{~h}\left(\mathrm{Y}_{3}\right)$ :

$\mathrm{Y}=\mathrm{B}_{0}+\mathrm{B}_{1} \mathrm{X}_{1}+\mathrm{B}_{2} \mathrm{X}_{2}+\mathrm{B}_{3} \mathrm{X}_{3}+\mathrm{B}_{11} \mathrm{X}_{1}^{2}+\mathrm{B}_{22} \mathrm{X}_{2}^{2}+$ $\mathrm{B}_{33} \mathrm{X}_{3}^{2}+\mathrm{B}_{12} \mathrm{X}_{1} \mathrm{X}_{2}+\mathrm{B}_{13} \mathrm{X}_{1} \mathrm{X}_{3}+\mathrm{B}_{23} \mathrm{X}_{2} \mathrm{X}_{3}+\mathrm{B}_{123} \mathrm{X}_{1} \mathrm{X}_{2} \mathrm{X}_{3}$

where $\mathrm{Y}$ is a dependent variable, $\mathrm{B}_{0}$ the arithmetic mean response of eight batches, and $\mathrm{B}_{1}, \mathrm{~B}_{2}$, and $\mathrm{B}_{3}$ are estimated coefficients for factors $\mathrm{X}_{1}, \mathrm{X}_{2}$ and $\mathrm{X}_{3}$, respectively. The main effects $\left(\mathrm{X}_{1}, \mathrm{X}_{2}\right.$ and $\left.\mathrm{X}_{3}\right)$ represent average result of changing one factor at a time from its low and high values. The interaction terms $\left(\mathrm{X}_{1} \mathrm{X}_{2}\right),\left(\mathrm{X}_{1} \mathrm{X}_{3}\right),\left(\mathrm{X}_{2} \mathrm{X}_{3}\right)$ show how the response changes when three factors are simultaneously changed. The polynomial term $\left(\mathrm{X}_{1} \mathrm{X}_{2} \mathrm{X}_{3}\right)$ is included to investigate non-linearity. The validity of the developed polynomial equations was verified by preparing check point formulation $(\mathrm{C})$.

\section{Drug release study}

A quantity of selected factorial formulations equivalent to $25 \mathrm{mg}$ of the drug was taken in the dialysis bag (cellophane membrane, molecular weight cutoff 10,000-12,000 Da; Hi-Media). The dialysis bag was then suspended in a flask containing $100 \mathrm{ml}$ of $0.1 \mathrm{~N} \mathrm{HCl}$ on a magnetic stirrer at $37 \pm 0.5^{\circ} \mathrm{C}$ at $100 \mathrm{rpm}$. Required quantity $(5 \mathrm{ml})$ of the medium was withdrawn at specific time periods $(1,2,3,4$, $6,8,10,12,24,32 \mathrm{~h}$ ) and the same volume of dissolution medium was replaced in the flask to maintain a constant volume. The withdrawn samples were filtered and then $5 \mathrm{ml}$ filtrate was made up to volume with $100 \mathrm{ml}$ of $0.1 \mathrm{~N} \mathrm{HCl}$. 
The samples were analyzed for drug release by measuring the absorbance at $252 \mathrm{~nm}$ using UV/Vis spectrophotometer. ${ }^{[16]}$

In vitro evaluation of intestinal mucoadhesion of nanoparticles

The Institutional Animals Ethical Committee (IAEC) of Al-Ameen College of Pharmacy, Bangalore, approved the protocol for the study. Male Sprague Dawley rats weighing 200-250 g were fasted overnight before the experiments, but allowed free access to water. A part of intestine (duodenum and jejunum) was excised under anesthesia and perfused with physiological saline to remove the contents of stomach. The cleaned portion was used immediately after preparation. A $50 \mathrm{mg}$ quantity of mucoadhesive nanoparticle sample that was suspended in phosphate buffer ( $\mathrm{pH}$ 6.8) was filled into the cleaned intestine, ligated and then incubated in physiological saline at $37^{\circ} \mathrm{C}$ for $30 \mathrm{~min}$. The liquid content of separated portion of intestine was then removed by injecting the air and the same was perfused with phosphate ( $\mathrm{pH}$ 6.8) for $2 \mathrm{~h}$, at a flow rate of $1 \mathrm{ml} /$ min. The intestine was cut open and the nanoparticles that remained in it were recovered with phosphate buffer (pH 6.8). The final volume of washing solution was mixed with $10 \mathrm{ml}$ of acetone solution and kept for $2 \mathrm{~h}$ for complete digestion of nanoparticles. After filtration through a $0.45-\mathrm{mm}$ filter paper, absorbance was determined spectrophotometrically at $252 \mathrm{~nm}$ (acyclovir) and gastric mucoadhesion was determined as the $\%$ of nanoparticles remaining in intestine after perfusion. ${ }^{[17]}$

\section{Drug-polymer interaction studies}

Differential scanning calorimetry (DSC) is one of the most powerful analytical techniques, which offers the possibility of detecting chemical interaction. Acyclovir (pure drug), PLGA, and physical mixtures of drug and polymer at different ratios $(1: 1,1: 1.5,1: 2,1: 2.5)$ were kept at $40 \pm 2{ }^{\circ} \mathrm{C} / 75 \pm 5 \%$ relative humidity $(\mathrm{RH})$. Samples at 0.1 , 2,3 and 6 months were withdrawn and sent for DSC analysis. Also, drug-polymer interaction for selected formulation of coated and uncoated nanoparticles was evaluated by DSC (Perkin-Elmer DSC 7, USA). Thermograms of acyclovir, polymer (PLGA), and mucoadhesive nanoparticles were obtained with $5^{\circ} \mathrm{C} / \mathrm{min}$ of heating rate at a temperature between $50^{\circ} \mathrm{C}$ and $280^{\circ} \mathrm{C}$.

\section{SEM photomicrographs}

The morphology of coated and uncoated nanoparticles was examined by scanning electron microscopy (SEM, JSM-5310LV scanning microscope Tokyo, Japan). The nanoparticles were mounted on metal stubs using double-sided tape and coated with a $150 \AA$ layer of gold under vacuum. Stubs were visualized under scanning electron microscope.

\section{RESULTS AND DISCUSSION}

Mucoadhesive drug delivery system prolongs the residence time of the dosage form at the site of application or absorption and facilitates an intimate contact of the dosage form with the underlying absorption surface, and thus contributes to improved and/or better therapeutic performance of the drug. Acyclovir is predominantly absorbed from upper GIT and specifically there are indications for its active absorption from the duodenum and jejunum regions of GIT. In commercially available dosage forms, the amount of drug absorbed is very low $(10-20 \%)$ due to short residence time of the dosage forms at the absorption site. As a result, most of the drug is excreted in the feces $(50-60 \%)$ in unabsorbed form. ${ }^{[18]}$ Hence, it can be envisaged that increasing the residence time at the absorption site can enhance the absorption and bioavailability of acyclovir. Therefore, it was decided to formulate and develop mucoadhesive nanoparticles of acyclovir and investigate its potential of optimizing delivery of the drug as compared to the presently used dosage forms which suffer from several drawbacks as mentioned.

Appropriate selection of the polymeric matrix is necessary in order to develop a successful nanoparticulate delivery system. Biodegradable polymers have received much attention in recent years. ${ }^{[19]}$ PLGA has been most extensively used because of its biocompatibility and biodegradability, with the degradation products formed at a slow rate, thus not affecting the normal cell function. PLGA degrades in vivo to lactic and glycolic acids, which are subsequently eliminated as carbon dioxide and water via the Krebs cycle. ${ }^{[2]}$ The release of drug from the nanoparticles depends on polymer degradation, which is governed by the nature of copolymer composition and its molecular weight. For this study, we used PLGA 50:50, which is known to hydrolyze at a faster rate than those containing a higher proportion of polylactic acid. ${ }^{[21]}$ Noveon AA-1 polycarbophil, USP is a high molecular weight acrylic acid polymer cross-linked with divinyl glycol. It provides excellent bioadhesive properties and has been used extensively to enhance the delivery of active ingredients to various mucus membranes. Acetone is used as a solvent for the preparation of PLGA nanoparticles due to its water 
miscible and comparatively non-toxic nature. ${ }^{[20]}$

All microsphere formulations were spherical in shape and possessed smooth surface as visualized under SEM [Figure 1]. Out of all mucoadhesive formulations developed according to the factorial design and the above-described method, MF2, MF5, MF6 and MF8 were found to be free flowing, i.e. non-sticky, but formulations MF1, MF3, MF4 and MF7 were found to be sticky. All formulations were white and powdery in appearance.

The particle size affects the biopharmaceutical, physicochemical and drug release properties of the nanoparticles. A graphical representation of the particle size of mucoadhesive nanoparticles obtained is given in Figure 1. Particle size is an important parameter because it has a direct relevance to the stability of the formulation. Larger particles tend to aggregate to a greater extent compared to smaller particles, thereby resulting in sedimentation. ${ }^{[16]}$ The amount of stabilizer used also has an effect on the properties of nanoparticles. If the concentration of stabilizer is too low, aggregation of the polymer will take place, whereas if too much stabilizer is used, drug incorporation could be reduced as a result of the interaction between the drug and stabilizer. ${ }^{[1]}$

The effect of the concentration of the polymers tested
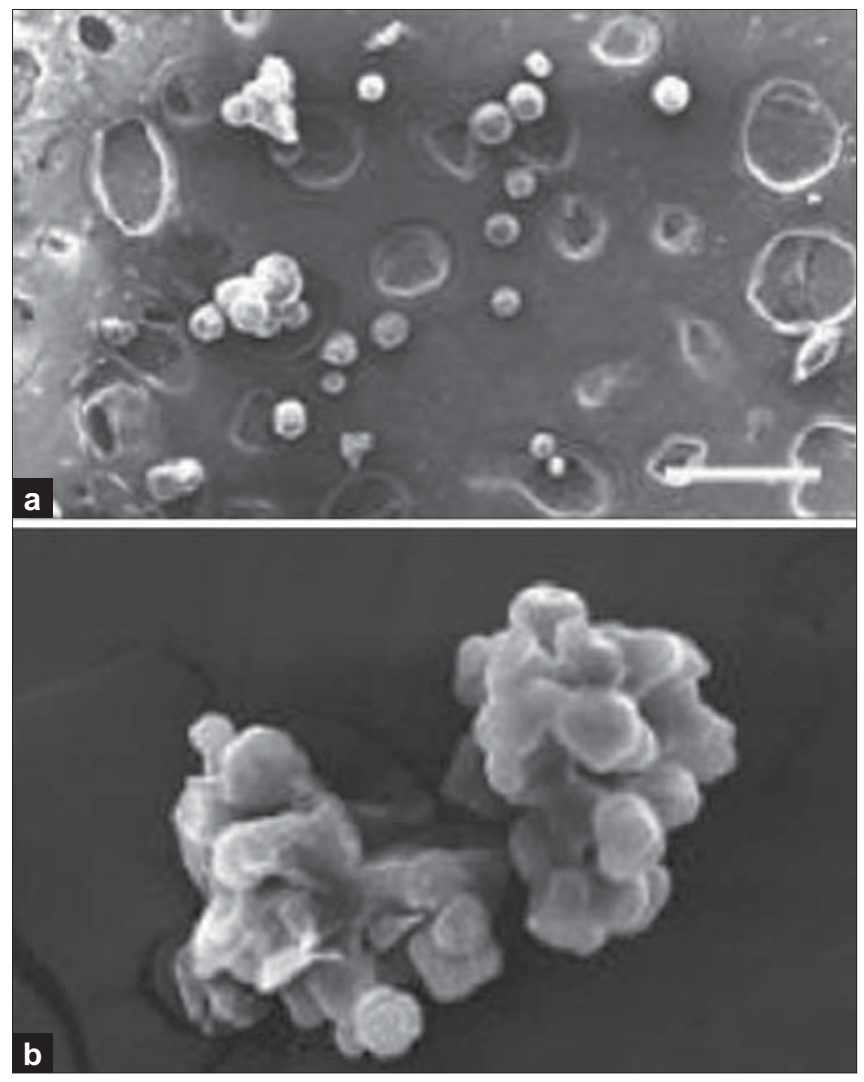

Figure 1: SEM of PLGA nanoparticles is negative or positive. A positive effect would imply that increasing the concentration causes the emulsion to have larger droplets, thereby leading to larger particles. A negative effect means that increasing the concentration causes the emulsion to be more stable, thereby leading to smaller particles. ${ }^{[17]}$

From Figures 2 and 3 and Table 1, it is seen that as drug: polymer (acyclovir: PLGA or acyclovir: polycarbophil) ratios increase from 1:0.875 to 1:1.25 (for PLGA) and from 1:0.6 to 1:0.9 (for polycarbophil), particle size and drug entrapment efficiency increase significantly. It also reveals that concentration of the stabilizer has a significant effect on particle size, but it has insignificant or negligible effect on drug entrapment efficiency of nanoparticles.

This can be explained by observing particle size and \% drug entrapment of mucoadhesive factorial formulations MF1 and MF2, and MF7 and MF8, where the drug: Polymer (PLGA) ratio increased from 1:0.875 to 1:1.25, with a constant concentration of stabilizer (pluronic F68), i.e. $0.3 \%$ for MF1 and MF2 and $0.2 \%$ for MF7 and MF8. The drug entrapment efficiency increased from 89.9 to $93.7 \%$ and from 80.09 to $86.26 \%$, respectively; also, the particle

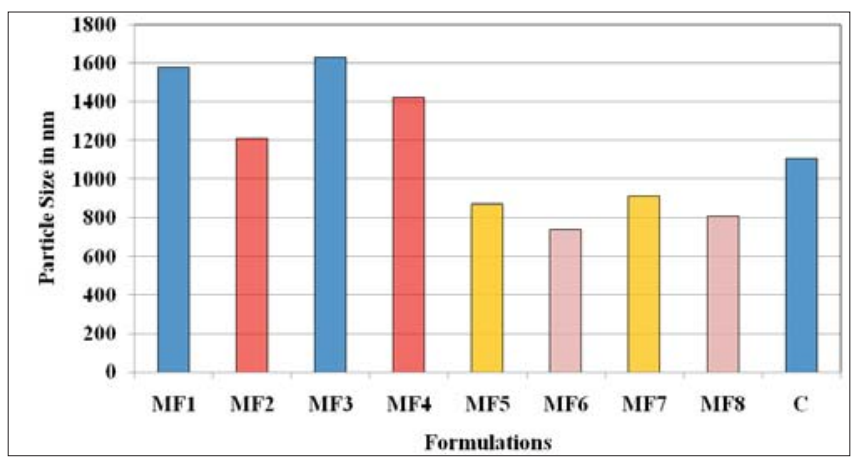

Figure 2: Comparison of particle size of mucoadhesive factorial formulations and check point formulation

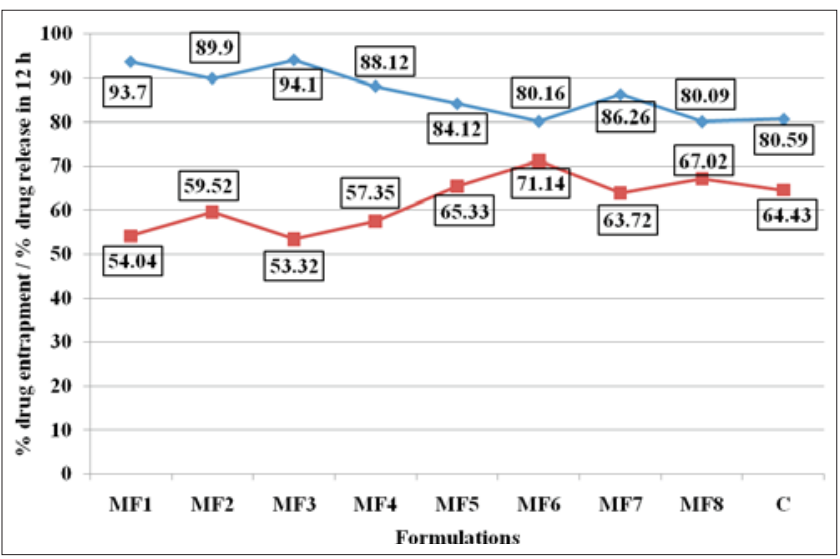

Figure 3: Comparison of \% drug entrapment and \% drug release in $12 \mathrm{~h}$ of factorial and check point formulations 
size increased from 1210 to $1580 \mathrm{~nm}$ and from 810 to $914 \mathrm{~nm}$, respectively.

In the same way, it can be explained with respect to mucoadhesive factorial formulations MF1 and MF5, and MF4 and MF8, where the drug: polymer ratio increased from 1:0.6 to 1:0.9, with a constant concentration of the stabilizer (pluronic F68), i.e. $0.3 \%$ for MF1 and MF5 and $0.2 \%$ for MF4 and MF8. The drug entrapment efficiency increased from 84.12 to $93.7 \%$ and from 80.09 to $88.12 \%$, respectively; also, the particle size increased from 870 to $1580 \mathrm{~nm}$ and from 810 to $1420 \mathrm{~nm}$, respectively.

But it has been observed for mucoadhesive factorial formulations MF1 and MF3, and MF6 and MF8, where the stabilizer concentration increased from 0.2 to $0.3 \%$, with a constant drug: polymer ratio, i.e. 1:1.25 for MF1 and MF3 and 1:0.875 for MF6 and MF8, that the particle size decreased from 163 to $1580 \mathrm{~nm}$ and from 810 to $740 \mathrm{~nm}$, respectively; but at the same time, there was an insignificant or a negligible change in the drug entrapment efficiency as it changed from 94.1 to $93.7 \%$ and from 80.09 to $80.16 \%$, respectively. Thus, it can be concluded that polymer and surfactant concentration has a significant effect on the particle size. However, there is insignificant or negligible effect of surfactant concentration on drug entrapment efficiency.

Drug release from nanoparticles and subsequent biodegradation are important for developing successful formulations. The release rate of nanoparticles depends upon i) desorption of the surface-bound/adsorbed drug; ii) diffusion through the nanoparticle matrix; iii) diffusion (in case of nanocapsules) through the polymer wall; iv) nanoparticle matrix erosion; and v) a combined erosion/ diffusion process. Thus, diffusion and biodegradation govern the process of drug release. ${ }^{[22]}$

It is generally anticipated for a bulk eroding polymer such as 50:50 PLGA to give an initial burst release followed by a controlled release, in contrast to the release pattern observed in other controlled release systems, for example, sustain release tablets, pellets and beads. In cases where there is an initial burst effect, the high initial release may be attributed to the presence of crystals of free and weakly bound drug on the surface of the particulate carriers. ${ }^{[23]}$

The mechanism of drug release from nanoparticles is determined by different physical-chemical phenomena. The exponent $\mathrm{n}$ has been proposed as indicative of the release mechanism. In this context, $n=0.43$ indicates Fickian release, $n=0.85$ indicates a purely relaxation (case II) and $>0.85$ indicates super case II controlled delivery. Intermediate values $0.43<\mathrm{n}<0.85$ indicate an anomalous behavior (non-Fickian kinetics) corresponding to coupled diffusion/polymer relaxation. ${ }^{[24]}$

The average percentage release was fitted into different release models: Zero-order, first-order and Higuchi's square root plot. The models giving a correlation coefficient close to unity were taken as the order of release. In vitro drug release data of all factorial formulations were subjected to goodness of fit test by linear regression analysis according to zero-order and first-order kinetic equations, Higuchi's and Korsmeyer-Peppas models to ascertain the mechanism of drug release. From the various parameters determined for drug release from nanoparticles based on Peppas model, Higuchi model and diffusion profile, it is evident that values of " $\mathrm{r}$ " for Higuchi plots of all mucoadhesive factorial formulations are close to unity, i.e. linear (drug release by diffusion). Diffusion exponent values " $n$ " of Peppas equation for MF1, MF2 and MF3 are 0.6446, 0.5074 and 0.6435 , respectively, and show non-Fickian diffusion, and for MF4, MF5, MF6, MF7 and MF8 are 0.4286, 0.3858, $0.3225,0.3942$ and 0.3311 , respectively, showing Fickian diffusion. Table 2 and Figure 4, shows almost zero-order drug release for all factorial formulations as correlation coefficient of zero order drug release is close unity than first order drug release correlation coefficient. It can be concluded that the different drug release rates may be attributed to different sizes of the nanoparticles. It is expected that as the particle size of PLGA nanoparticle is smaller, its surface area will be more and the drug release is faster. ${ }^{[17]}$

From the data of experimental design and parameters [Table 1] for mucoadhesive factorial formulations F1F8, polynomial equations for three dependent variables (particle size, \% drug entrapment and \% drug release in $12 \mathrm{~h}$ ) have been derived using Sigma plot software (Systat Software Inc., Version 3.0, Richmond, CA software.)

\begin{tabular}{|c|c|c|c|c|}
\hline Formulation & $\begin{array}{c}\text { Correlation } \\
\text { coefficient } \\
\text { (zero order) }\end{array}$ & $\begin{array}{c}\text { Correlation } \\
\text { coefficient } \\
\text { (first order) }\end{array}$ & $\begin{array}{c}\text { Kinetic/ } \\
\text { diffusion } \\
\text { exponent"n" }\end{array}$ & $\begin{array}{c}\text { Correlation } \\
\text { coefficient } \\
\text { (Higuchi model) }\end{array}$ \\
\hline MF1 & 0.989 & 0.0091 & 0.6446 & 0.9897 \\
\hline MF2 & 0.983 & 0.0040 & 0.5074 & 0.9832 \\
\hline MF3 & 0.975 & 0.0150 & 0.6435 & 0.9759 \\
\hline MF4 & 0.973 & 0.0110 & 0.4286 & 0.973 \\
\hline MF5 & 0.961 & 0.0020 & 0.3858 & 0.9618 \\
\hline MF6 & 0.936 & 0.0040 & 0.3225 & 0.936 \\
\hline MF7 & 0.956 & 0.0060 & 0.3942 & 0.956 \\
\hline MF8 & 0.937 & 0.0010 & 0.3311 & 0.937 \\
\hline
\end{tabular}


The equation derived for particle size is:

$\mathrm{Y}_{1}=1136.7+11.75 \mathrm{X}_{1}-36.75 \mathrm{X}_{2}+303.25 \mathrm{X}_{3}$

$+13.25 \mathrm{X}_{1} \mathrm{X}_{2}-8.25 \mathrm{X}_{2} \mathrm{X}_{3}+53.25 \mathrm{X}_{1} \mathrm{X}_{3}$

The equation derived for $\%$ drug entrapment is:

$\mathrm{Y}_{2}=87.0563+2.4887 \mathrm{X}_{1}-0.0862 \mathrm{X}_{2}$

$+4.3987 \mathrm{X}_{3}-0.5487 \mathrm{X}_{1} \mathrm{X}_{2}+0.4313 \mathrm{X}_{2} \mathrm{X}_{3}-0.0438 \mathrm{X}_{1} \mathrm{X}_{3}$

The equation derived for $\%$ drug release in $12 \mathrm{~h}$ is:

$\mathrm{Y}_{3}=63.07-2.2175 \mathrm{X}_{1}+1.1725 \mathrm{X}_{2}-5.2750 \mathrm{X}_{3}$

$-0.45 \mathrm{X}_{1} \mathrm{X}_{2}-0.2925 \mathrm{X}_{2} \mathrm{X}_{3}-0.0075 \mathrm{X}_{1} \mathrm{X}_{3}$

In Equation (4), negative sign for coefficient of $\mathrm{X}_{2}$ indicates that the particle size of nanoparticles increases when the concentration of pluronic $\mathrm{F} 68$ is decreased and positive sign for coefficients of $\mathrm{X}_{1}$ and $\mathrm{X}_{3}$ indicates positive effect of polymer concentrations (PLGA and polycarbophil) on the particle size.

In Equation (5), positive sign for coefficients of $\mathrm{X}_{1}$ and $\mathrm{X}_{3}$ indicates that the \% drug entrapment increases when the concentrations of PLGA and polycarbophil increase and negative sign for coefficient of $\mathrm{X}_{2}$ indicates that $\%$ drug entrapment of nanoparticles increases when the concentration of pluronic F68 decreases. Also, the value of coefficient for $\mathrm{X}_{2}(-0.0862)$ shows insignificant or negligible effect of an independent variable on a dependent variable.

In Equation (6), negative sign for coefficient of $X_{1}$ and $X_{3}$ indicates that the $\%$ drug release in $12 \mathrm{~h}$ increases when the concentrations of PLGA and polycarbophil decrease and positive sign for coefficient of $\mathrm{X}_{2}$ indicates positive effect of pluronic F68 concentration on \% drug release in $12 \mathrm{~h}$.

Validity of the above equations was verified by designing check point formulation (C). The particle size, $\%$ drug entrapment and $\%$ drug release in $12 \mathrm{~h}$ from the equations derived and those observed from experimental results are summarized in Table 3. The closeness of predicted and observed values for particle size and \% drug entrapment indicates validity of derived equations for dependent variables.

Graphical presentation of the data can help to show the relationship between response and independent variables. Graphs gave information similar to that of the mathematical equations obtained from statistical analysis. The response surface graphs of particle size and \% drug entrapment, \% drug release in $12 \mathrm{~h}$ are presented in Figures 5-7 respectively.

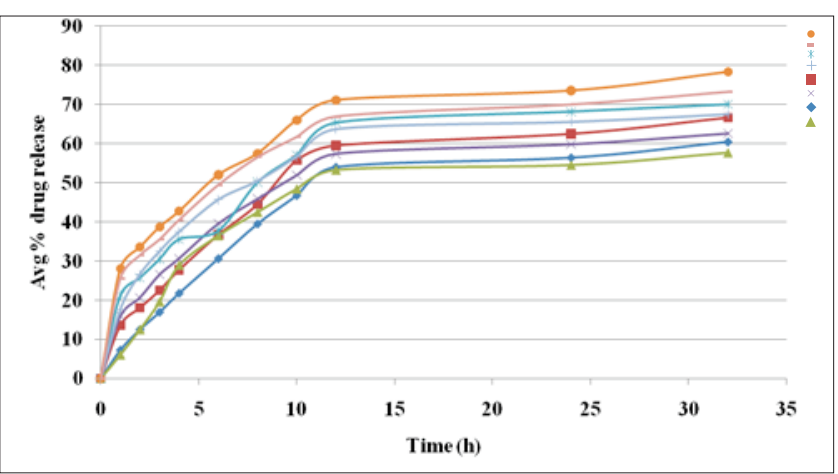

Figure 4: Average \% drug release of mucoadhesive factorial formulations

Table 3: Parameters of check point formulation

\begin{tabular}{|c|c|c|c|c|c|c|}
\hline \multirow[t]{2}{*}{ Formulation } & \multicolumn{3}{|c|}{ Predicted values } & \multicolumn{3}{|c|}{ Observed values } \\
\hline & $\begin{array}{c}\text { Particle } \\
\text { size } \\
(\mathrm{nm})\end{array}$ & $\begin{array}{l}\% \text { Drug } \\
\text { entrapment }\end{array}$ & $\begin{array}{c}\% \\
\text { Drug } \\
\text { release } \\
\text { in } 12 \mathrm{~h}\end{array}$ & $\begin{array}{c}\text { Particle } \\
\text { size } \\
(\mathrm{nm})\end{array}$ & $\begin{array}{c}\% \text { Drug } \\
\text { entrapment }\end{array}$ & $\begin{array}{c}\% \\
\text { Drug } \\
\text { release } \\
\text { in } 12 \mathrm{~h}\end{array}$ \\
\hline $\mathrm{C}$ & 1012 & 83.61 & 66.03 & 1107 & 80.59 & 64.43 \\
\hline
\end{tabular}

The response surface plots and contour plots illustrate that as the concentration of polymers (PLGA and polycarbophil) increases, the value of dependent variable, i.e. particle size, increases; also, as the concentration of stabilizer (pluronic F68) increases, the value of dependent variable, i.e. particle size, decreases.

Similarly, the response surface plots and contour plots for \% drug entrapment shows positive effects of independent variable, i.e. polymer concentrations (PLGA and polycarbophil) and negative effect of other independent variable, i.e. concentration of stabilizer (pluronic F68).

But in contrast to this illustration, the response surface plot and contour plot for $\%$ drug release in $12 \mathrm{~h}$ shows negative effect of independent variable, i.e. polymer concentrations (PLGA and polycarbophil) and positive effect of independent variable, i.e. concentration of stabilizer (pluronic F68) on \% drug release in $12 \mathrm{~h}$.

Mucoadhesion involves different kinds of interaction forces between mucoadhesive materials and mucus surface, such as electrostatic attraction, hydrogen bonding, Van der Waals forces and mechanical interpenetration and entanglement. ${ }^{[19]}$

Spectrophotometric method $(\lambda \max 252 \mathrm{~nm}$ ) used to measure in vitro mucoadhesive capacity of developed formulations shows the $\%$ intestinal retention of mucoadhesive nanoparticles in the rat intestinal mucosa. The adhesion properties of nanoparticles increased with increasing concentration of mucoadhesive polymer (polycarbophil); 
among the various concentrations of polycarbophil, better mucoadhesion was observed for MF2 and MF6 formulations as $67.3 \%$ and $62.1 \%$, respectively [Table 1$]$.

DSC gives information regarding the physical properties like crystalline or amorphous nature of the samples. The DSC thermogram of acyclovir [Figure 8a] shows an exothermic peak at 267.03 corresponding to its melting temperature, which was not detected in the thermograms for acyclovir-loaded coated and uncoated nanoparticles of PLGA 50:50 [Figures $8 \mathrm{~b}$ and $\mathrm{c}$. It has been shown by a couple of authors that when the drug does not show its exothermic peak in the formed nanoparticles, it is said to be in the amorphous state. ${ }^{[2]}$ Hence, it could be concluded that in both the prepared PLGA nanoparticles (coated and uncoated), the drug was present in the amorphous phase and may have been homogeneously dispersed in the PLGA matrix.

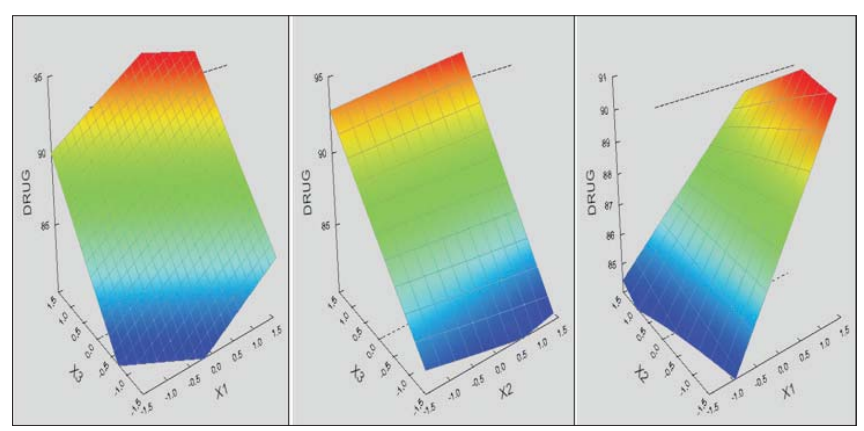

Figure 5: Response surface plots of effects of factorial variables on $\%$ drug entrapment

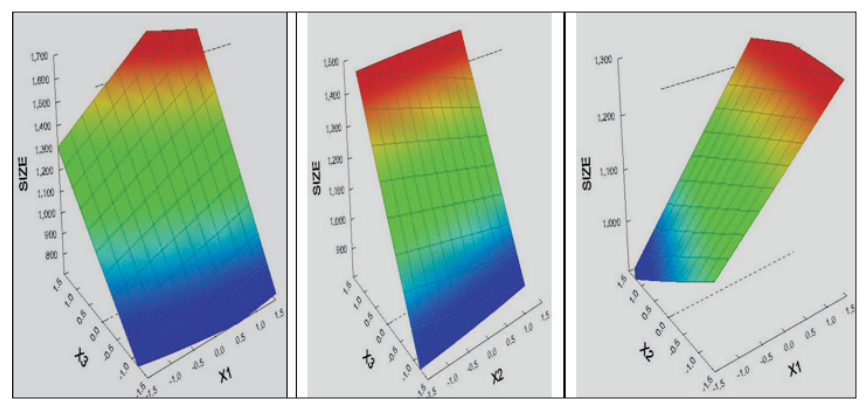

Figure 6: Response surface plots of effects of factorial variables on particle size

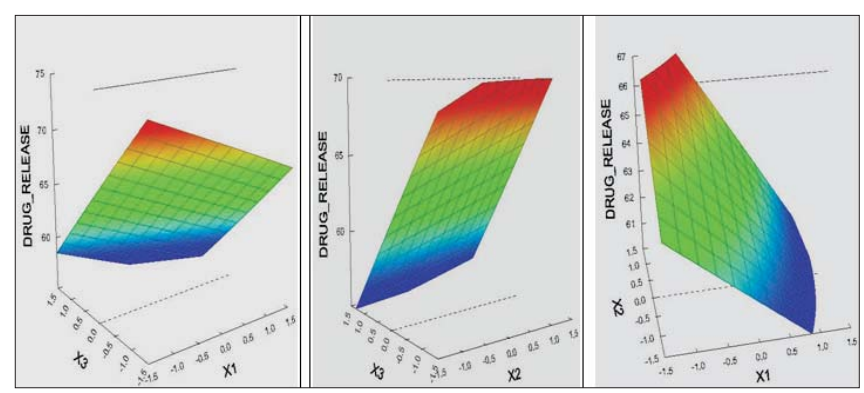

Figure 7: Response surface plots of effects of factorial variables on $\%$ drug release in $12 \mathrm{~h}$

\section{CONCLUSION}

PLGA nanoparticles were prepared by the solvent deposition method and were characterized as "mucoadhesive" by coating with mucoadhesive polymer, polyacrylic acid (polycarbophil). The application of factorial design gave a statistically systematic approach for the formulation of nanoparticles with the desired particle size, high entrapment efficiency and sustained drug release. Drug: polymer ratio and concentration of surfactant were found to influence the particle size and \% drug release of acyclovir-loaded PLGA mucoadhesive nanoparticles. In vitro drug release study of all formulations (MF1-MF8) showed $57.71-78.31 \%$ drug release in $32 \mathrm{~h}$. The release was found to follow Fickian as well as non-Fickian diffusion mechanism with almost zero-order drug release for all batches. In vitro intestinal mucoadhesion of nanoparticles showed that the adhesion properties of nanoparticles increased with increasing concentration of mucoadhesive polymer (polycarbophil). These preliminary results indicate that acyclovir-loaded mucoadhesive PLGA nanoparticles could be effective in sustaining drug release for a prolonged period. Further studies are needed to confirm its performance in vivo.

Thus, the above investigation involves extensive and in-depth holistic studies of mucoadhesive and site-specific

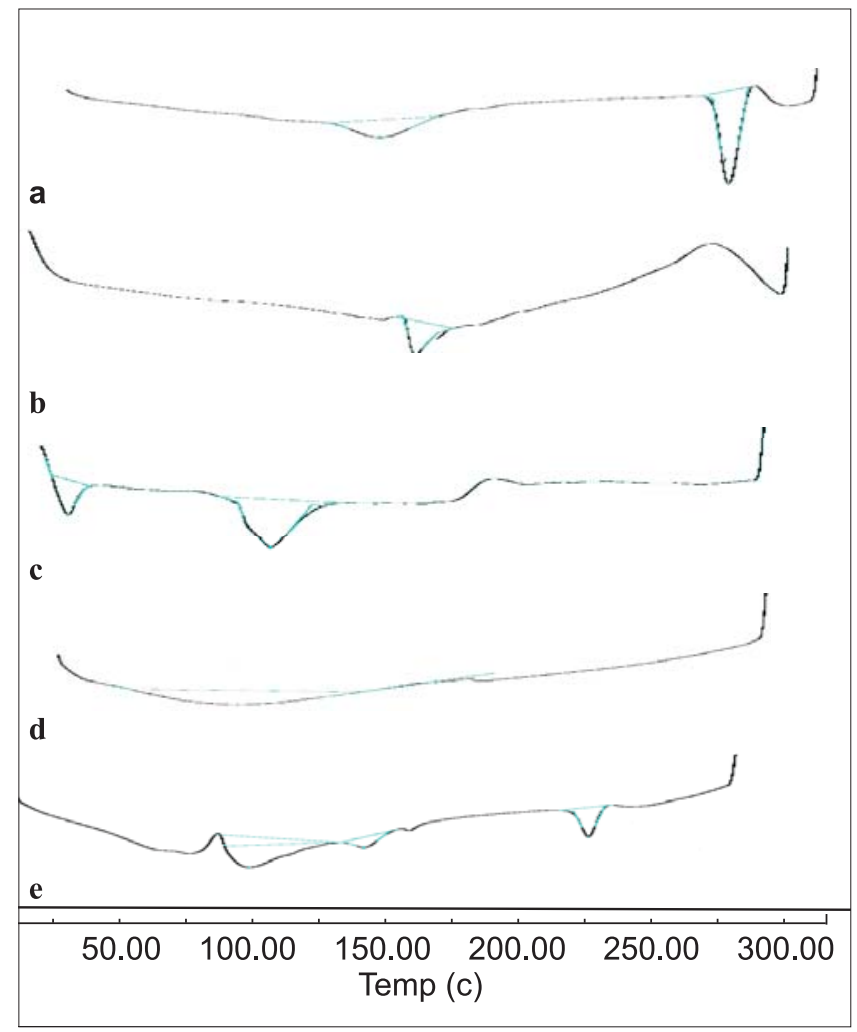

Figure 8: DSC thermograms 
nanoparticles tailored to achieve controlled release of predetermined quantities of the drug, resulting in not only optimizing drug delivery but also development of a platform technology which has extensive patenting potential and can be useful for so many other such drugs.

\section{REFERENCES}

1. Tran T, Druce JD, Catton MC, Kelly H, Birch CJ. Changing epidemiology of genital herpes simplex virus infection in Melbourne, Australia, between 1980 and 2003. Sex Transm Infect 2004;80:277-9.

2. Emmert DH. Treatment of common cutaneous Herpes Simplex Virus infections. Am Fam Physician 2000;61:1697-704.

3. Wagstaff AG, Faulds D, Goa KL. Aciclovir: A reappraisal of its antiviral activity, pharmacokinetic properties and therapeutic efficacy. Drugs 1994;47:153-205.

4. Ruhnese M, Sandstorm F, Andersson B. Treatment of recurrent genital herpes simplex infection with acyclovir. J Antimicrob Chemother 1985;16:621-8.

5. Fuertes I, Miranda A, Millan M, Caraballo I. Estimation of the percolation thersholds in acyclovir hydrophilic matrix tablets. Eur J Pharm Biopharm 2006;64:336-42.

6. Jalon De EG, Blanco-Prieto MJ, Ygartua P, Santoyo S. Increased efficacy of acyclovir-loaded microparticles against herpes simplex virus type 1 in cell culture. Eur J Pharm Biopharm 2003;56:183-7.

7. Rossi S, Sandri G, Ferrari F, Bonferoni MC, Caramella C. Buccal delivery of acyclovir from $1 \mathrm{~ms}$ based on chitosan and polyacrylic acid. Pharm Dev Technol 2003;8:199-208.

8. O'Brien JJ, Campoli-Richards DM. Acyclovir: An updated review of its antiviral activity, pharmacokinetic properties and therapeutic efficacy. Drugs 1989;37:233-309.

9. Allemann E, Leroux JC, Gurny R. Polymeric nano- and microparticles for the oral delivery of peptides and peptidomimetics. Adv Drug Deliv Rev 1998;34:171-89.

10. Smart, JD, Kellaway IW, Worthington HEC. J Pharm Pharmacol 1984;36:295.

11. Kamath KR, Park K. In Encyclopedia of Pharmaceutical Technology. Vol. 10. New York: Marcel Dekker; vol.10, 1988. p. 133-64.

12. Phutane P, Shidhaye S, Lotlikar V, Ghule A, Sutar S, Kadam V. In vitro evaluation of novel sustained release microspheres of glipizide prepared by the emulsion solvent diffusion-evaporation method. J Young Pharma 2010;2:35-41.

13. Fessi H, Puisieux F, Devissaguet JP, Ammoury N, Benita S. Nanocapsules deposition by interfacial polymer deposition following solvent deplacement. Int J Pharm 1989;55:R1-4.

14. Freitas MN, Marchetti JM. Nimesulide PL. A microspheres as a potential sustained release system for the treatment of inflammatory diseases. Int J Pharma 2005;13:201-11.

15. Gohel M, Patel M, Amin A, Agarwal A, Dave R, Bariya N. Formulation design and optimization of mouth dissolve tablets of nimesulide using vacuum drying technique. AAPS Pharm Sci Tech 2004;5:36.

16. Jain S, Srinath MS, Narendra C, Reddy SN, Sindhu A. Development of a floating dosage form of ranitidine hydrochloride by statistical optimization technique. J Young Pharma 2010;2:342-9.

17. Ramteke S, Umamaheshwari RB, Jain NK. Clarithromycin based oral sustained release nanoparticulate system. Indian J Pharm Sci 2006;68:479-84.

18. Park GB, Shao Z, Mitra AK. Acyclovir permeation enhancement across intestinal and nasal mucosae by bile salt-acylcarnitine mixed micelles. Pharm Res 1992;9:1262-7.

19. Feng SS, Mu L, Win KY, Huang G. Nanoparticles of biodegradable polymers for clinical administration of paclitaxel. Curr Med Chem 2004;11:413-24.

20. Murakami H, Kawashima Y, Niwa T, Hino T, Takeuchi H. Influence of the degrees of hydrolyzation and polymerization of poly(vinylalcohol) on the preparation and properties of poly(-lactide-co-glycolide) nanoparticles. Int J Pharm 1997;149:43-9.

21. Jain RA. The manufacturing techniques of various drug loaded biodegradable poly(lactide-co-glycolide) (PLGA) devices. Biomaterials 2000;21:2475-90.

22. Ashish K, Mehta P, Yadav KS, Krutika KS. Nimodipine Loaded PLGA Nanoparticles: Formulation optimization using factorial design, characterization and in vitro evaluation. Curr Drug Deliv 2007;4:185-93

23. Nixon JR. Release characterization of microcapsules. In: Lim F, editor. Biomedical applications of microcapsulation. Boca Raton, FL: CRC Press; 1983.

24. Costa P, Lobo JM. Modeling and comparison of dissolution profiles. Eur J Pharm Sci 2001;13:123-33.

25. Ritger PL, Peppas NA. A simple equation for description of solute release: Fickian and non-Fickian release from nonswellable devices in the form of slabs, spheres, cylinders or discs. J Control Release 1992;5:23-36.

How to cite this article: Bhosale UV, Devi VK, Jain N. Formulation and optimization of mucoadhesive nanodrug delivery system of acyclovir. J Young Pharmacists 2011;3:275-83.

Source of Support: Nil, Conflict of Interest: None declared.

Author Query

Q1: Please define legends???

\section{Staying in touch with the journal}

1) Table of Contents (TOC) email alert Receive an email alert containing the TOC when a new complete issue of the journal is made available online. To register for TOC alerts go to http://www.jyoungpharm.in/signup.asp.

\section{2) RSS feeds}

Really Simple Syndication (RSS) helps you to get alerts on new publication right on your desktop without going to the journal's website. You need a software (e.g. RSSReader, Feed Demon, FeedReader, My Yahoo!, NewsGator and NewzCrawler) to get advantage of this tool. RSS feeds can also be read through FireFox or Microsoft Outlook 2007. Once any of these small (and mostly free) software is installed, add http://www.jyoungpharm.in/rssfeed.asp as one of the feeds. 